\title{
Musik Metal dan Nilai Religius Islam: Tinjauan Estetika Musik Bermuatan Islami dalam Penampilan Purgatory
}

\author{
Sujud Puji Nur Rahmat ${ }^{1}$, G.R. Lono Lastoro Simatupang, dan A. Harsawibawa \\ Universitas Gadjah Mada
}

\begin{abstract}
Metal Music and Islamic Religious Values: The Aesthetics Review of Islamic Music in Purgatory Performance. Metal music is closely related to violence, rebellion, and abuse. Therefore, the metal band is also associated with those images. Purgatory, a metal band in Jakarta, however, is trying to establish a distinctive image to those of metal bands in common. They are to promote Islamic religious values in their music and performances. In this paper, the writers seek to understand how this band remains having their fans with these issues. This study uses an ethnographic approach. Data collection is carried out by doing the participatory observation. The writers actively got involved in the metal music performances and also other various activities. Based on the research results, it can be concluded that there are three dimensions of the aesthetics perceptions, i.e. carrying Islamic religious values, having a characteristic that displays the characteristics of metal music, and broadcasting good values that support Mogerz, fans of Purgatory, to keep on attracted to the band and their music.
\end{abstract}

Keywords: Islamic metal music; purgatory; mogers

\begin{abstract}
ABSTRAK
Musik metal terkait dengan isu kekerasan, pemberontakan, kesewenang-wenangan. Oleh karenanya, band metal juga lekat dengan citra-citra itu. Namun demikian, Purgatory, band metal dari Jakarta, mencoba memunculkan citra yang berbeda. Mereka mengusung nilai-nilai religius islami dalam karya musik dan pertunjukannya. Dalam tulisan ini, penulis berupaya untuk memahami cara band ini tetap memiliki penggemar dengan isu-isu yang diusung tersebut. Penelitian ini menggunakan pendekatan etnografi. Pengumpulan data dilakukan dengan cara observasi-partisipasi. Penulis mengikuti dalam peristiwa-persitiwa pementasan musik metal dan juga berbagai aktivitas yang mengelilinginya. Berdasarkan penelitian dapat disimpulkan bahwa ada tiga dimensi persepsi estetika yaitu mengusung nilai-nilai religius Islami, memiliki kekhasan yang menampilkan ciri musik metal, dan mensyiarkan nilai-nilai kebaikan yang mendorong Mogerz, yakni para penggemar Purgatory tetap tertarik dengan band itu dan musiknya.
\end{abstract}

Kata kunci: musik metal islami; purgatory; mogers

\section{Pendahuluan}

Komersialisasi atau bisnis musik merupakan salah satu fenomena yang terjadi di berbagai belahan dunia, termasuk Indonesia. Industri musik atau bisnis musik mengarah pada penjualan komposisi, rekaman, dan pertunjukan musik (Antrie dan Sitta, 2011:28). Orang dan organisasi yang beroperasi di dalam industri ini, antara lain: para musisi yang menggubah dan mempertunjukkan karya-karyanya, perusahaan dan profesional yang menciptakan dan menjual musik rekaman (misalnya penerbit, produser, studio, teknisi, label rekaman, toko musik dan ritel, organisasi hak pertunjukan); pihak yang menampilkan pertunjukan musik langsung (agen, promotor, panggung musik, kru jalan), para

Alamat korespondensi: Prodi Pengkajian Seni Pertunjukan dan Seni Rupa, Sekolah Pascasarjana Universitas Gadjah Mada. Gedung Lengkung, Jln. Teknika Utara, Pogung Yogyakarta. E-mail: sujud_pnr@yahoo.com; HP. +62 81232727232 . 
profesional yang membantu musisi terkait karier mereka (manajer, pengacara hiburan), pihak yang menyiarkan musik (radio satelit dan siaran), jurnalis, pengajar, produsen instrumen musik, dan lain-lain. Peran industri dapat membentuk suatu identitas atau karakteristik musik di suatu wilayah. Hal serupa juga dapat dilihat melalui peranan seni pertunjukan yang diprakarsai oleh generasi muda seniman muslim dari kawasan Paris. Mereka berusaha mengembangkan sensibilitas budaya atau artistik yang tetap kondusif bagi kepekaan Islam. Karya seni pertunjukan yang diproduksi diharapkan dapat memperluas pemahaman mengenai politik indrawi Islam, serta praktik estetika dan etika, di mana hiburan, rekreasi, dan industri budaya dianggap semakin menentukan keberlanjutan budidaya diri yang saleh (Jouili, 2014: 1079-1104).

Dalam dunia bisnis musik di Indonesia, berbagai cara dilakukan oleh musisi dan pelakupelaku bisnis musik lainnya agar karya-karya musik Indonesia mendapat perhatian masyarakat, salah satunya musik dangdut di era pasca-Soeharto sekitar tahun 2003 dalam lingkup budaya populer. 'Inulmania' berkontribusi pada ruang dialogis baru mengenai posisi ideologis yang saling bertentangan tetapi dapat diekspresikan dan diperdebatkan. Tubuh Inul menjadi panggung bagi berbagai aktor budaya untuk mencoba atau melatih demokrasi yang muncul di Indonesia (Weintraub, 2008).

Hal yang sama juga terjadi musik dangdut yang diprakarsai Rhoma Irama yang memasukkan nilainilai religius Islam melalui grup musik dangdutnya, Soneta Group, yang berdiri sejak 11 Desember 1970. Lirik lagu-lagu Soneta Group menceritakan pesan-pesan moral, kritik sosial, dan nilai-nilai religi Islam. Soneta berikrar bahwa musik mereka berasaskan amar makruf nahi munkar (mengajak kebaikan, menjauhi keburukan). Hal ini sejalan dengan jargon Soneta hingga kini, "The Voice of Moslem" (Suara Muslim). Tema dakwah memang kerap dipakai Soneta Group dalam menggarap lagu dangdutnya, misalnya: lagu Lailiahaillaliah dalam album musik untuk film Raja Dangdut (1978); album khusus bertajuk Haji (1983); lagu Setetes Air Hina dalam album Renungan dalam Nada (1983) yang mengutip Al-Quran Surat Ath-Thariq ayat
5-7, mengajak menjauhi sikap sombong karena manusia berasal dari proses biologis yang "hina". Lagu-lagunya memuat petuah dari hadist Nabi Muhammad SAW mengenai peringatan menjaga lima hal baik dalam hidup sebelum lima yang buruk datang. Hal tersebut muncul dalam album musik untuk film Cinta Segitiga (1979).

Tahun 2010, Soneta Group meluncurkan album bertajuk Azzo. Pada dasarnya, album ini hanya memuat satu lagu baru, yakni $A z z a$. Selain $A z z a$, lagu-lagu lain dalam album tersebut adalah karya lama yang didaur ulang, seperti lagu Kehilangan, Keramat, Rana Duka, Tabir, Kepalsuan, Sebujur Bangkai, 1001 Macam, Patah Hot. Dalam album tersebut juga terdapat satu lagu berjudul GalaGala yang merupakan versi bahasa Indonesia dan aransemen dari lagu India, Jana-Jana. Kata Azza adalah potongan dari kata Azzawajallah yang berarti memuliakan Tuhan. Tidak hanya tema religius, Soneta juga mengulas persoalan perilaku negatif masyarakat, seperti kebiasaan begadang, berjudi, mabuk-mabukan, dan mengkonsumsi narkoba. Berdasarkan data penjualan kaset dan jumlah penonton film-film Rhoma Irama, William H. Frederick memprediksikan terdapat sekitar 15 juta jiwa penggemar dan pengikut Rhoma Irama hingga pertengahan 1980-an. Sesuai data sensus 1982, jumlah penduduk Indonesia saat itu sekitar 146 juta jiwa. Berarti, jumlah penggemar dan pengikut Rhoma Irama berkisar sekitar 10\% penduduk Indonesia.

Keberhasilan Soneta Group, khususnya Rhoma Irama, antara lain disebabkan oleh penggunaan nilai-nilai religius Islam, yang merupakan agama mayoritas di Indonesia. Menurut Saidi (2012), Rhoma Irama dan Soneta Group adalah imaji populer, bukan menggunakan musik untuk berdakwah melainkan menarik agama dan Tuhan masuk ke dalam musiknya untuk mempopulerkan musik dan grupnya lalu kemudian dijadikan alasan untuk berdakwah. Bahkan, tuduhan Rhoma Irama menjual ayat-ayat suci Al-Qur'an pun pernah diarahkan padanya. Tuduhan ini berujung pada sidang pertanggungjawaban di hadapan para ulama sekitar bulan Desember 1983. Selain itu, pelarangan tampil di TVRI juga sempat ia alami selama 11 tahun (1977-1988). 
Masalah negosiasi pertunjukan juga terlihat dalam ranah musik tradisional seperti halnya penelitian yang dilakukan oleh Harnish tentang Wayang Sasak di Lombok yang menyoroti cerita, boneka, proses pertunjukan, musik yang mencerminkan konteks sosiokultural Lombok yang berubah, dan cara para praktisi harus bernegosiasi tentang dunia yang berbeda dari modernisasi, berupaya untuk mengubah estetika agar bisa diterima oleh masyarakat Lombok (Harnish, 2003: 91-120).

Setidaknya dalam satu dekade belakangan, sering pula dijumpai kelompok-kelompok musik populer yang mengusung lagu-lagu bernuansa religi menjelang hari-hari besar keagamaan. Tidak hanya kelompok musik pengusung genre-genre musik arus utama (mainstream) yang mencoba mengangkat nilai-nilai religius Islam, melainkan juga kelompok yang beraliran minoritas, misalnya metal. Salah satu grup musik metal yang melakukan strategi ini adalah Purgatory. Seolah mengikuti jejak Rhoma Irama dan Soneta Groupnya, Purgatory merupakan salah satu representasi penggunaan nilai-nilai Islam oleh sebuah grup musik saat ini.

Tulisan ini mencoba menelaah dimensi estetika dari penampilan Purgatory yang menampilkan repertoar bermuatan nilai religius Islam dalam balutan musik metal. Di satu sisi, memasukkan nilainilai religius ke dalam repertoar musikal bukanlah suatu hal yang benar-benar istimewa. Namun, di lain sisi, musik metal merupakan musik minoritas (bukan arus utama) dan kerap diasosiasikan dengan nilai-nilai yang jauh dari religiusitas (Weinstein, 2000: 2). Hal ini terlihat menarik ketika didiskusikan dalam kaitannya dengan nilai-nilai religius.

Penelitian ini menggunakan pendekatan etnografi. Pengumpulan data dilakukan dengan cara observasi-partisipasi. Penulis mengikuti peristiwapersitiwa pementasan musik metal dan juga berbagai aktivitas yang mengelilinginya. Dalam observasi ini, penulis menangkap dan mencatat informasiinformasi atau gejala-gejala yang kiranya penting. Selain itu, observasi ini ditunjang dengan wawancara dan kajian pustaka. Data yang telah dikumpulkan kemudian dikontruksi berdasarkan kerangka pemikiran yang digunakan sehingga menghasilkan suatu narasi yang utuh tentang dimensi estetika penampilan Purgatory yang menyajikan musik bermuatan nilai religius Islam.

\section{Purgatory dan Nilai Islami}

Sampai saat ini, banyak perdebatan mengenai timbulnya label-label Islami di dalam bisnis musik. Pengkompilasian nilai-nilai dan pengkategoriannya tergantung pada basis ayat Al-Quran atau hadist Nabi yang serupa. Pengkategorian mengusulkan seperangkat nilai-nilai Islam yang terkait dengan praktik kesenian (Ishak \& Osman, 2016: 103112). Beragam kompleksitas Islam khususnya seni diproyeksikan bisa merefleksikan budaya material dunia Islam, dari asal - keragaman budaya dan praktik Islam dalam rangka dakwah atau syiar agama (Shaw, 2012: 1-34). Kemunculannya juga bertujuan untuk berbagai kepentingan seperti berdakwah, keuntungan materi, sebagai pelengkap, atau hanya ekspresi semata, masing-masing pihak memiliki alasan dan cara pandang masingmasing. Namun, harus diakui bahwa Purgatory memasukkan muatan nilai-nilai Islami sebagai salah satu strategi untuk mempopulerkan grupnya.

Konsep popular, dalam hal ini, tidak hanya berkonotasi meraih keuntungan material-finansial, melainkan juga populer dalam arti bisa meraih banyak pendengar-penikmat-penggemar. Strategi ini diwujudkan dalam bentuk lirik lagu, kontrak perjanjian tanpa musyrik dan maksiat, penggunaan nama rasul sebagai penamaan penggemar, dan penggunaan simbol bulan sabit dan bintang sebagai logo grup.

Label-label Islami masih dipakai dan diminati oleh pelaku musik dan masyarakat Indonesia yang notabene merupakan negara dengan penduduk pemeluk Islam terbesar dunia. Berdasarkan data kependudukan dari media Pew Research Center's Forum on Relegion \& Public Life (2011), jumlah penduduk dunia yang beragama Islam telah mencapai 1,6 miliar jiwa pada tahun 2011, atau $23,4 \%$ dari jumlah penduduk dunia. Sementara itu, di Indonesia jumlah penduduk yang beragama Islam berjumlah 205 juta jiwa, atau 85,9\% dari jumlah penduduk Indonesia. Perjalanan band metal di negara mayoritas Islam yang penuh dengan peperangan, seperti grup band heavy metal 
Acrassicauda dari Irak, terinspirasi oleh kelompokkelompok seperti Metallica, Slayer, dan Slipknot. Band ini mulai menulis lirik lagu dan bermain musik metal pada tahun 2001. Selanjutnya, band tersebut juga melakukan beberapa pertunjukan sebelum perang dimulai pada tahun 2003. Peningkatan tindakan pencegahan keamanan di seluruh Irak menjadikan band tersebut sulit untuk berlatih. Irak mulai menerima ancaman pembunuhan dari kelompok-kelompok pemberontak dan fundamentalis agama yang menuduh mereka setan atau anti-ibadah. Irak hancur karena perang. Sementara itu, Acrassicauda berjuang untuk tetap bersama-sama, tetap hidup, dan selalu berusaha untuk mewujudkan band mereka tetap hidup (Capper \& Sifre, 2009).

Sebelum tahun 2002, Purgatory sama seperti grup metal lain. Lirik-lirik lagu yang dibawakan oleh Purgatory banyak menceritakan setan, kekerasan, dan lain sebagainya yang berkisar anti-ketuhanan/ agama. Namun, sejak tahun 2003, atau sepuluh tahun setelah berdiri, Purgatory mengubah total konsep bermusiknya, khususnya pada lirik-lirik lagu yang menyiratkan pula upaya mensyiarkan agama (Islam). Hal tersebut membuat Purgatory dikenal dengan grup metal Islami. Putranto (2009: 8) mengemukakan bahwa citra (image) yang terbentuk dari artis/band itu merupakan persepsi yang ditangkap publik saat menerima berbagai informasi yang diberikan artis/band tersebut secara konstan, misalnya yang ditimbulkan dari musik, lirik, gaya/penampilan, attitude, sampul album dan desain merchandise hingga opini sang artis.

Beberapa lagu dalam reportoar Purgatory yang memuat nilai-nilai religius Islam adalah M.O.G.S.A.W (Massenger OfGod Shalallahu Alaihi Wassallam) yang ada pada album "7:172"—nama album tersebut diambil dari Al Quran, yaitu 7 yang artinya surat ke 7 (Al A'raaf) dan 172; Lords of War (Ahli Naar), Downfall: The Battle of Uhud, Jonah, 55:13, Dahsyatnya Kekufuran, dan Taubat.

Selain lagu yang bermuatan Islami, kontrak kerjasama dengan Purgatory pun diupayakan memuat nilai-nilai itu. Terdapat peraturan yang harus dijalankan pihak pengundang ketika bekerjasama dengan Purgatory yaitu tidak boleh ada sponsor yang dilarang Islam, seperti minuman beralkohol—beberapa pertunjukan musik metal biasanya disponsori oleh perusahaan minuman beralkohol. Inti dari pemasaran Islam adalah prinsip maksimalisasi nilai berdasarkan untuk kesejahteraan masyarakat yang lebih luas, sehingga dapat membantu untuk menciptakan kerangka pemasaran etis global yang bernilai - dimuat dan membangun kerjasama yang harmonis dan bermakna antara produsen dan muslim khususnya sebagai target pasar (Saeed, Ahmed, \& Mukhtar, 2001: 127-142). Intinya, tidak boleh ada sesuatu dalam bentuk apapun di dalam suatu acara yang dapat mengurangi nilai-nilai Islam. Jika syarat tersebut tidak bisa dipenuhi oleh pihak penyelenggara, Purgatory tidak akan menyetujui untuk tampil di acaranya.

Elemen lain yang bermuatan nilai religius Islami adalah penamaan penggemar. Purgatory menamakan penggemarnya dengan Mogerz: Mog merupakan akronim dari Messenger of God (Rasulullah SAW), sedangkan 'erz' yang artinya lebih ke pelaku atau pengikut. Kata Mog diambil dari salah satu judul lagu Purgatory di album “7.127", yaitu "M.O.G.S.A.W”.

Namun, dalam perkembangannya, kini kata Mogerz tidak hanya untuk sebutan penggemar Purgatory saja, melainkan juga untuk mereka
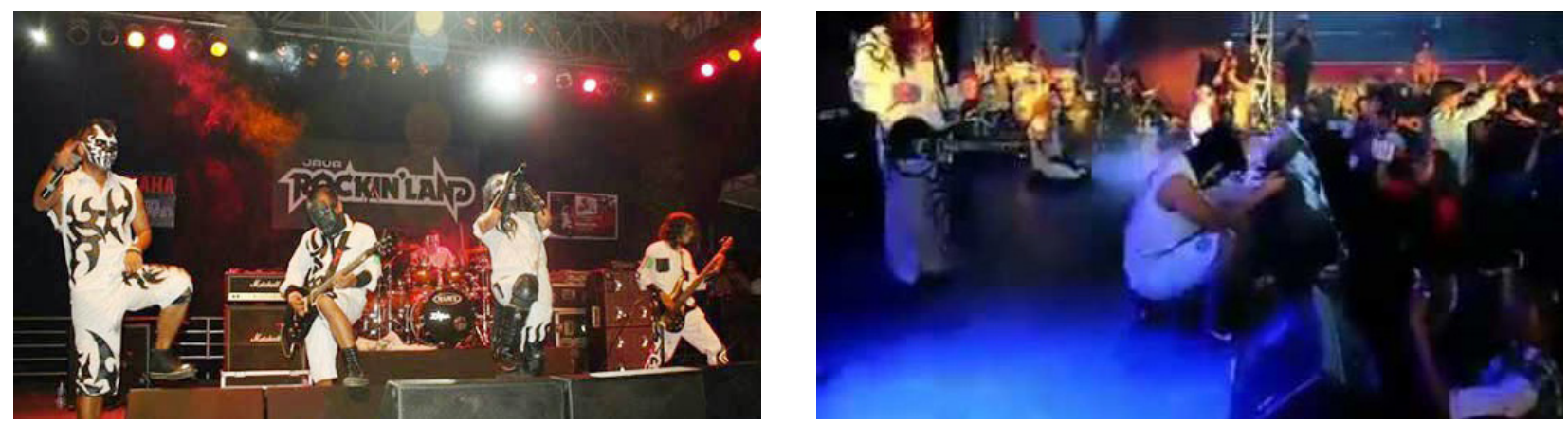

Gambar 1. Ekspresi Purgatory dalam Membawakan Lagu Mogsaw. (Foto: www.tribun.com) 
(Purgatory) sendiri. Purgatory beralasan, mereka tidak mau mengikuti kepada sesuatu yang salah. Oleh karena itu, mereka beranggapan, penggemarnya jangan mengikuti Purgatory; karena Purgatory merasa belum tentu benar. Purgatory dan penggemarnya adalah satu umat Nabi Muhammad SAW, bahkan demikian juga seluruh manusia yang hidup setelah Rasulullah

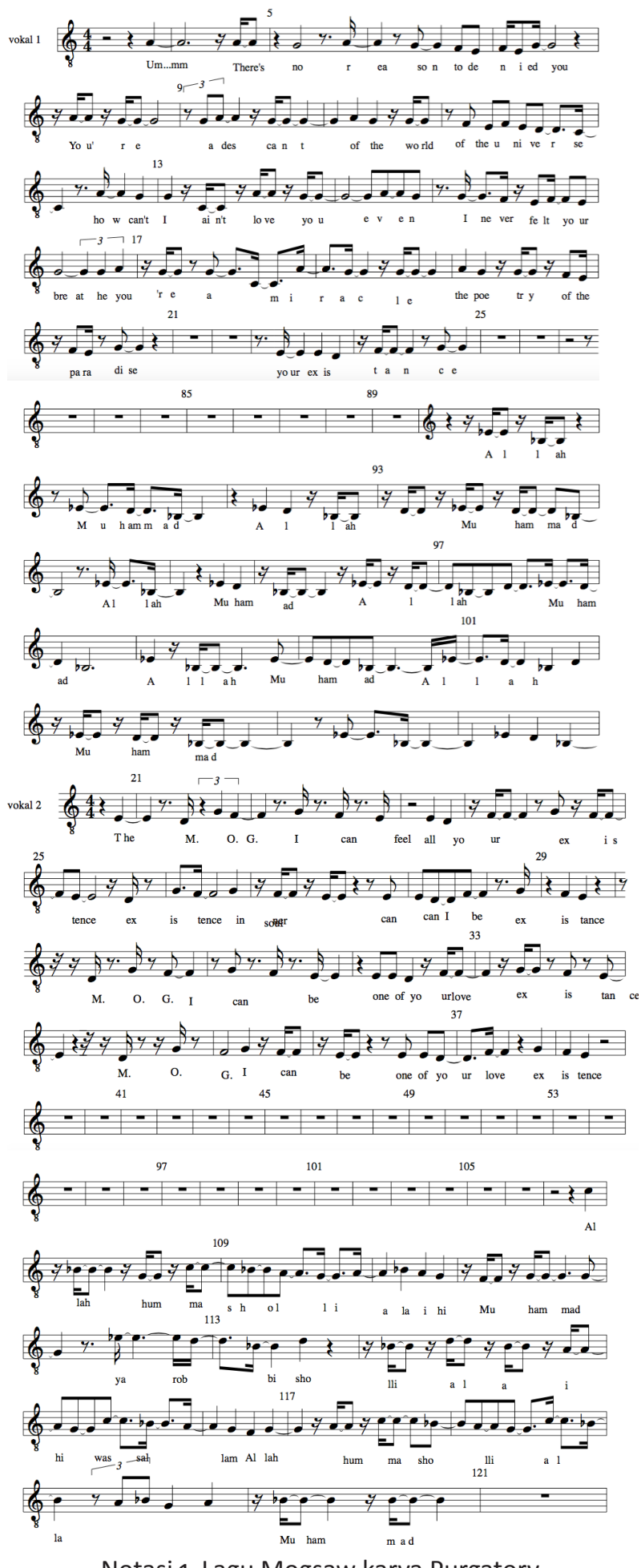

Notasi 1. Lagu Mogsaw karya Purgatory.
SAW. Mogerz pun bermetamorfosa maknanya menjadi wadah silaturahim bagi orang-orang yang berkeinginan dan bertahan dalam menghindari dosa dalam kehidupan sehari-hari.

Beberapa orang yang menjadi anggota Mogerz karena mendengarkan musik Purgatory yang berisikan ajakan mendekatkan kepada Tuhan. Selain itu, anggota Mogerz juga ada yang tidak mengetahui musik Purgatory, tetapi bergabung karena memiliki visi yang sama. Anggota Mogerz tidak hanya beragama Islam, melainkan ada juga yang non-Islam. Bahkan, ada beberapa anggota Mogerz yang dahulu beragama non-Islam menjadi Islam (mualaf) antara lain setelah mendengarkan musik Purgatory. Para Mogerz sangat bangga menggunakan logo Purgatory yang berupa bulan sabit dan bintang sebagai salah satu cara memasukkan seni visual sebagai upaya menghadirkan yang dapat dikenali dalam objek sebagai sebuah logo yang cukup dikenal oleh publik muslim di Indonesia (George, 1998: 693-713). Logo juga merupakan sebuah ungkapan menyuruh kepada kebaikan jika terbukti kebaikan ditinggalkan (tidak diamalkan), dan melarang dari kemungkaran jika terbukti kemungkaran dikerjakan (hisbah) untuk mencari hubungan antara kegiatannya dan pengembangan seni dan kerajinan dalam Islam (Stilt, 2010: 473-475).

Aspek lain dari Purgatory yang juga mengusung nilai Islami adalah logo kelompok (Gambar 3). Purgatory menggunakan simbol bulan sabit dan bintang sebagai logo grup. Gambar bulan sabit dan kadang disertai bintang di atasnya merupakan simbol yang kerap ditemui. Simbol ini kebiasaanya ditemui di sekitar kawasan Timur Tengah atau negara berpenduduk Islam. Simbol bulan sabit dan bintang seringkali dikaitkan dengan kegiatan umat Islam pada masa kini. Logo grup tersebut dijadikan desain utama pada setiap merchandise yang diproduksi oleh Purgatory, antara lain kaos, gambar tempel, pin, poster, emblem, tas, celana, jaket, gantungan kunci, stik drum, dan gelas. Selain menjadi salah satu sumber pendapatan, penjualan merchandise ini sekaligus juga menjadi media promosi dan pembangun citra (image) kelompok musik tersebut.

Menurut catatan sejarah, simbol bulan bintang baru muncul dan dipakai kaum musilimin 
di masa pemerintahan kekhalifahan Utsmaniyah di Turki. Setelah berhasil menguasai Konstantinopel (sekarang Istanbul) pada tahun 1453, mereka mengadopsi lambang kota itu sebagai panji pasukan Utsmaniyah. Legenda menyebutkan bahwa Sultan Utsman, penguasa saat itu, bermimpi melihat dua ujung bulan sabit membentang dari ujung bumi yang satu hingga ujung lainnya. Hal itu diartikan sebagai pertanda kebaikan dan kejayaan sehingga ia memilih untuk mengadopsi lambang kota yang ditaklukkannya sebagai simbol Dinasti Utsmaniyah yang dibangunnya.

\section{Dimensi Estetika}

Estetika merupakan persoalan yang sangat erat kaitannya dengan seni. Tidak jarang, seni dan estetika dipandang sebagai satu entitas: seni berarti estetika, yang benilai estetika pasti merupakan seni. Namun, seperti yang diungkapkan Kardi Laksono (Laksono, Anggreni Purba, \& Dona Hapsari, 2015), semenjak Baumgarten merumuskan teori estetika di masa modern, konsep seni dan estetika mengalami perubahan yang sangat drastis; estetika bukan saja soal keindahan semata, melainkan juga persepsi (2015: 81). Menurut Martin Seel, terdapat tiga jenis persepsi estetika: estetika kontemplasi (aesthetic contemplation), estetika karena kesesuaian (aesthetic correspondence), dan imajinasi (aesthetic imagination) (Von Appen, 2007).

Kontemplasi estetika tidak berupaya memahami, menginterpretasikan, atau mendefinisikan apapun. Kontemplasi estetika tidak berurusan dengan makna, melainkan murni pada kenampakan inderawi suatu objek atau situasi (Von Appen, 2007: 11). Sebelumnya para kaum sufi sudah banyak melakukan kontemplasi untuk berhubungan dengan sang Khalik menggunakan musik (Frishkopf, 2012: 148-156). Artinya, pada dimensi kontemplasi ini, pendengar dan penggemar Purgatory tidak berada dalam tataran memahami dan memaknai penampilan dan repertoar-repertoar band itu yang mengusung nilai-nilai religius Islami. Oleh karena itu, tidak mengherankan apabila di lapangan ditemui bahwa penggemar Purgatory tidak hanya mereka yang menganut agama Islam, melainkan juga yang memeluk agama selain Islam. Hal ini dapat dipahami dengan perspektif kontemplasi bahwa sesuatu dapat menarik perhatian karena tampilannya, kenampakannya, atau caranya terdengar. Hentakan drum, raungan gitar, dentuman bass, serta suara vokal bisa jadi memberikan daya tarik tersendiri bagi pendengar Purgatory.
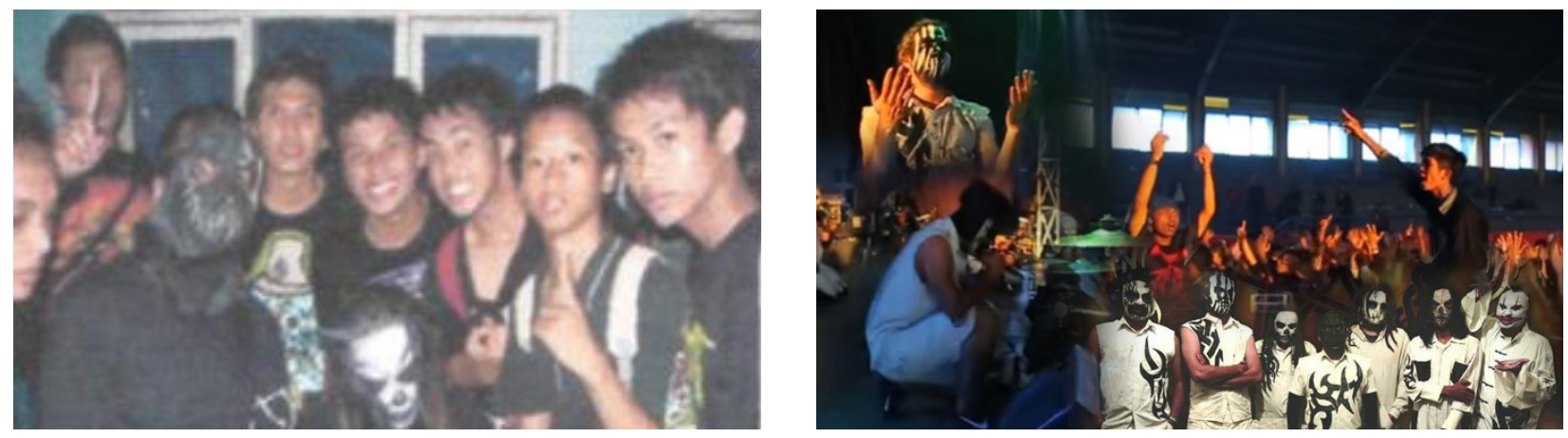

Gambar 2. Sekumpulan Penggemar Purgatory yang disebut Mogerz. (Foto: Sujud Puji Nur Rahmat, 2016)
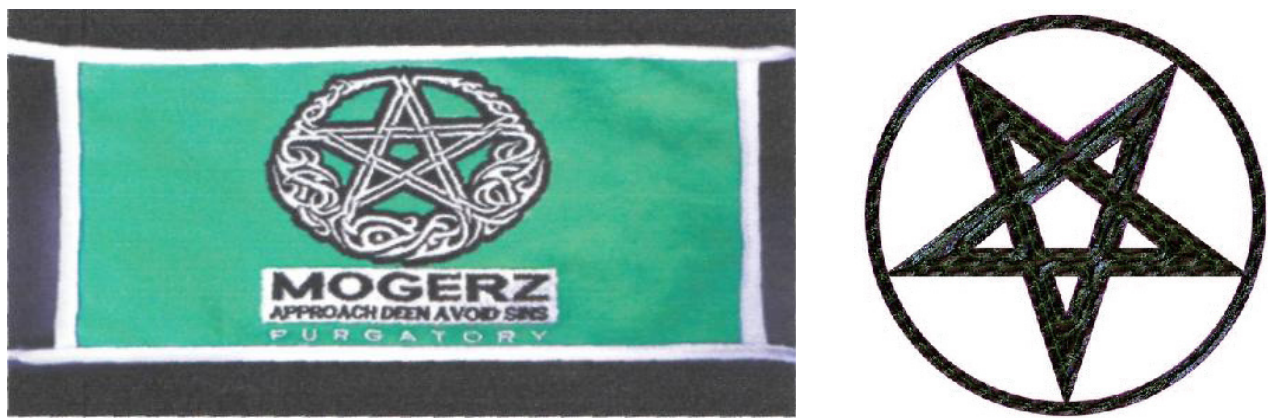

Gambar 3. Logo Purgatory yang berupa Bulan Sabit dan Bintang. (Foto: Sujud Puji Nur Rahmat, 2017) 
Artikulasi bunyi perkusi digunakan untuk memainkan aksen pada bass drum yang menggambarkan suasana dengan kesan tegas. Hal ini berimbas pada penonton yang menyaksikan pertunjukan Purgatory. Bunyi tersebut menimbulkan reaksi berupa gerakan tubuh yang sesuai dengan irama yang dibawakan. Dalam hal ini, tidak terlihat ada batasan pada faktor penikmat. Ditinjau dari faktor penikmat terdapat pembauran dari semua penonton yang hadir menyaksikan pertunjukan tersebut. Sebagai contoh, pada iringan lagu Mogsaw, pukulan bass drum dan snare lebih sering jatuh pada ketukan-ketukan bawah (down beat) sehingga nuansa beat rock akan lebih terasa saat memainkan pola ritme seperti ini (Notasi 2).

Pada tataran ini, Purgatory sebenarnya bisa saja tetap mempertahankan repertoar-repertoar "konvensional" khas band metal. Hal ini disebabkan oleh makna repertoar yang tidak menjadi daya tarik utama dalam penampilan mereka, melainkan sajian musik semata. Namun, band tersebut juga memiliki gagasan ideal mengenai sebuah kelompok musik yang bisa mendorong masyarakat, dalam hal ini penggemar dan komunitasnya, untuk melakukan hal-hal yang positif.

Dimensi kedua, yakni persepsi estetika yang muncul karena kesesuaian (aesthetic correspondence), dapat dipahami melalui nilai-nilai yang diusung Purgatory yang bersifat paralel dengan nilai-nilai Islam, agama yang mayoritas dipeluk oleh warga Negara Indonesia. Repertoar-repertoar Purgatory yang bermuatan nilai religius Islami menjadi daya tarik bagi pendengar-penggemar karena adanya kesesuaian dengan tuntunan hidup (agama) manusia (penggemarnya).

Terdapat beberapa nilai-nilai yang diajarkan dalam Islam yang diusung oleh Purgatory dalam karya-karya mereka: (1) bertauhid, mengakui bahwa tidak ada Tuhan selain Allah, (2) percaya kepada Al-Quran, menjadikan Al-Quran sebagai pedoman hidup, (3) Percaya kepada Rasul, menjadikan Rasul sebagai orang yang patut ditiru, (4) amanah, mengutamakan kepentingan umum di atas kepentingan pribadi, (5) tanggungjawab, melakukan segala kegiatan dengan baik dan jujur, (6) mengamalkan kebersihan hati, pakaian, bangunan, dan alam sekitar dalam kehidupan sehari-hari, menjauhi hawa nafsu dan emosi, (7) berdisiplin, mempunyai etika dan profesionalisme yang tinggi, (8) bekerjasama, mengamalkan sikap tolong-menolong dalam berkehidupan, (9) bersyukur, mengakui dan merenungkan bahwa semua yang didapat merupakan pemberian Tuhan, dan (10) menyebarkan syiar Islam.
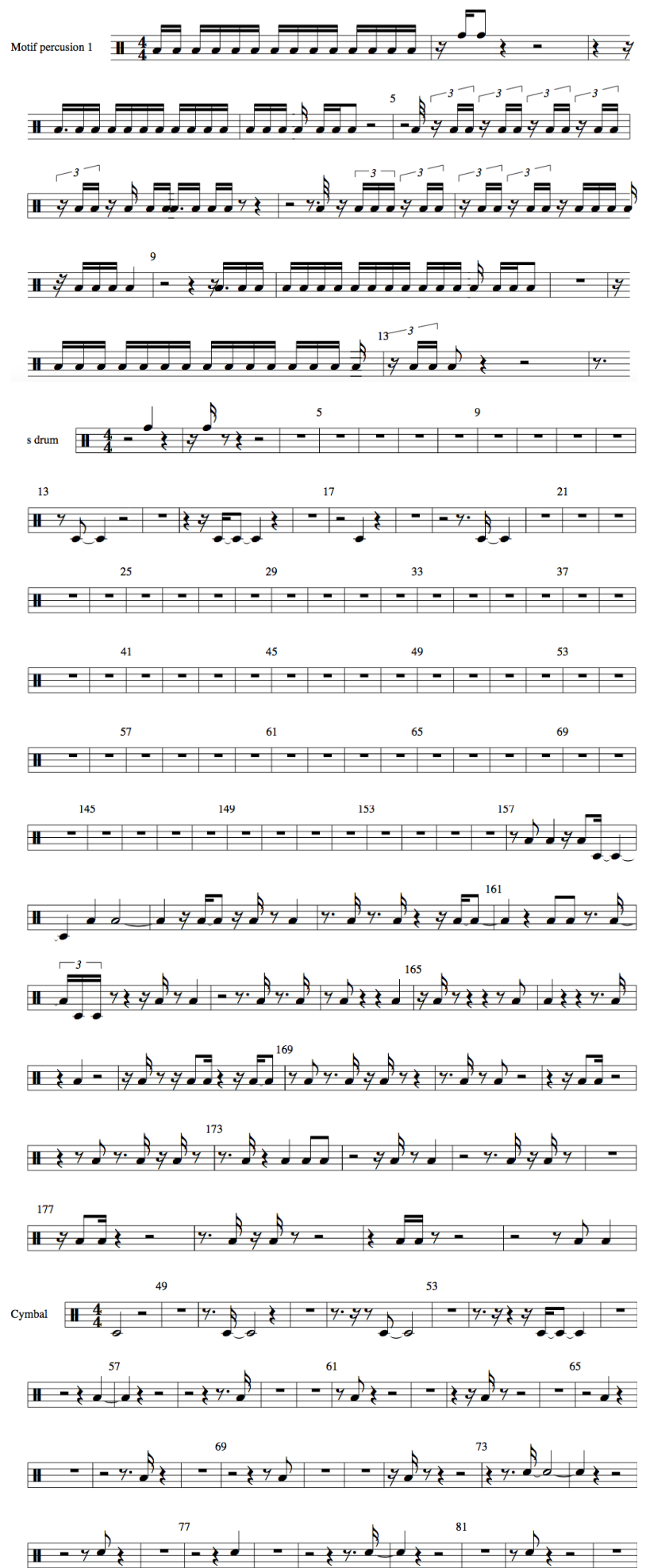

Notasi 2. Pukulan Bass Drum dan Snare Menunjukkan Nuansa Beat Rock. 
Unsur islami dimasukkan pada pertengahan komposisi lagu Mogsaw melalui syair sholawat Nabi Muhammad SAW. Selain itu, dari segi iringan, unsur rebana dimasukkan sebagai salah satu ciri musik bernuansa islami. Perpaduan drum dan rebana juga menghasilkan karakter suara sedang dan rendah. Bunyi pada bagian masuknya instrumen rebana ini menggambarkan suasana islami, gembira, dan tegas. Rebana merupakan alat musik ritmis yang menambah kesan bahwa musik ini memiliki nilai islami. Bahan dari instrumen rebana yang terbuat dari kayu dan membran dari kulit hewan menghasilkan suara logam kemricik ketika dipukul menjadikannya suara unik yang berbunyi secara bersamaan ketika digabungkan dengan distorsi musik metal dari Purgatory. Fungsi utama dari instrumen perkusi ini bermacam-macam, antara lain sebagai penggerak dinamika, pengatur tempo, dan membuat variasi pukulan. Berbagai unsur tersebut dapat mempengaruhi suasana musik yang diharapkan (Notasi 3).

Pada tataran ini, Purgatory dan karyanya berupaya untuk merefleksikan nilai-nilai Islami yang dijadikan pijakan bagi band itu dalam menampilkan citra diri disesuaikan dengan jalan kebenaran. Musik dan aspek kehidupan lainnya memang saling terkait satu sama lain. Nilai-nilai religius, misalnya, memiliki keterkaitan dengan musik. Aspek-aspek tersebut atau tingkah laku lainnya dalam kehidupan manusia memiliki keterkaitan yang menumbuhkan pemahaman mengenai suatu kebudayaan, salah satunya melalui studi musik (Irawati, 2017: 3). Intinya, ada kesesuaian antara musik dengan aspek kehidupan lainnya termasuk religi.

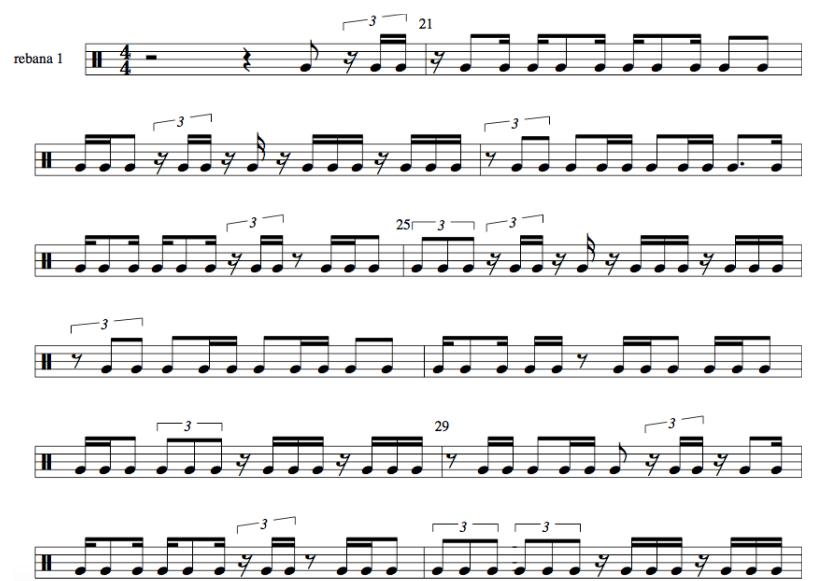

Notasi 3. Notasi instrumen rebana yang digunakan pada lagu Mogsaw.
Dimensi ketiga, yakni: aesthetic imagination, muncul dari bentuk dan isi suatu karya bisa bermakna bagi mereka yang mempersepsikannya. Kendati demikian, seperti yang dikatakan oleh von Appen, sulit untuk membedakan antara bentuk dan isi dari musik, terlebih dalam gabungan musik instrumental dan vokal. Kendati demikian, dalam konteks ini, bentuk dan isi dapat dibedakan berturut-turut menjadi struktur musik (aspek kebentukan musik) dan isi pesan yang ingin disampaikan. Sebagai contoh Purgatory memadukan sholawat Nabi Muhammad saw dengan lirik berbahasa Inggris. Adapun syair lagu tersebut adalah sebagai berikut.

\section{Lirik Lagu Mogsaw}

Uhmm, there's no reason to denied you

You're a descent of the world of the Universe

How can't I ain't love you, even I never felt your breathe

You're a miracle the poetry of paradise

Tidak ada alasan untuk mengingkari $\mathrm{Mu}$

Kau adalah utusan untuk bumi dari alam semesta

Bagaimana bisa aku tidak mencintaimu

Meskipun aku tidak pernah merasakan nafasmu

Kau adalah keajaiban, puisi surga

The M.O.G I can feel all

Your existence, inner soul, can I be

One of your love, one to serve you

I'll give my life, all my life, I'm yours, your martyr

Utusan Allah, aku bisa merasakannya

Keberadaan kau, dalam jiwa, dapatkah aku menjadi satu cintamu, satu untuk melayanimu

Aku akan memberikan hidupku, seluruh hidupku, aku milikmu, syahid mu.

Alone perceiving in silent dark before going down

And now you'll see what you've done to me

When I'm crying to myself, I realized that you're the one Imagine if you're not mine, I will definitely blind

Sendiri mengartikan di kegelapan sunyi sebelum turun Dan sekarang kau akan melihat apa yang telah kau lakukan

Ketika aku menangis sendiri, aku menyadari bahwa kau adalah tujuannya (orangnya)

Bayangkan jika kau bukan milikku, aku pasti akan buta

The M.O.G I can feel all

Your existence, inner soul, can I be

One of your love, one to serve you

I'll give my life, all my life, I'm yours, your martyr 
Utusan Allah, aku bisa merasakannya

Keberadaan kau, dalam jiwa, dapatkah aku menjadi satu cintamu, satu untuk melayanimu

Aku akan memberikan hidupku, seluruh hidupku, aku milikmu, syahid mu.

You change your vision, control your lust, believe me Cause everything will be proved with the truth at the last Death soon will come, God never shows you'll never know, whether you meet the dark or you'll be in the bright

Kau mengubah pengelihatanmu, mengendalikan nafsumu, percayalah kepadaku

karena semuanya akan dibuktikan dengan kebenaran pada akhirnya

Kematian akan segera datang, Tuhan tidak pernah menunjukkannya

Kau tidak akan pernah tahu

Apakah kau bertemu dengan kegelapan atau akan berada pada titik terang

Allah... Muhammad

Allahumma sholli alaibi Muhammad, ya robbi sholli alaibi wassalam

Lirik ini menceritakan besarnya rasa cinta kepada Nabi Muhammad. Hal ini terlihat pada bait pertama lagu dalam kalimat "kau adalah utusan alam semesta”. Melalui kalimat tersebut tidak ada alasan untuk tidak mencintainya. Ketika merasa kehilangan arah dan tujuan, panutan yang seharusnya diingat adalah Rasulullah. Melalui sosok ini, umat muslim menjadikannya panutan dalam kehidupan serta mengikuti ajarannya. Ajarannya mengingatkan pada tujuan sejatinya hidup. Ketika mengingkarinya dan tidak mengakuinya, manusia pasti akan kehilangan arah karena tidak ada petunjuk yang mendorong ke jalan yang benar. Rasulullah adalah utusan Allah yang keberadaannya ada di dalam jiwa setiap umatnya meski belum pernah melihat wajahnya. Sebagai umat pengikutnya, kaum muslim akan menyerahkan segala yang ada di diri untuk meyakininya, menjadi bagian darinya sebagai umat yang bersahaja sehingga tercapai hidup yang bahagia di dunia dan akhirat.

Lirik ini juga berisi sudut pandang dakwah, yaitu: pesan Rasulullah agar umatnya mengubah cara pandang terhadap dunia dan mengendalikan hawa nafsu. Mampu mengendalikan hawa nafsu berarti tahan terhadap godaan, tetap berada di jalan Allah karena Dia yang akan menunjukan segala sesuatunya di akhir kehidupan. Banyak rahasia Illahi yang tidak diketahui dan tidak pernah bisa diramalkan. Allah punya rahasia sedangkan manusia hanya perlu mengikuti ajarannya. Allah tidak akan menunjukkan diri-Nya tetapi manusia disadarkan pada hal-hal yang baik/buruk yang terjadi pada dirinya. Lirik lagu ini menambahkan sholawat sebagai salah satu identitas utamanya untuk menyampaikan pesan rohani. Musik metal biasanya menjadi bentuk lain karena terlenanya manusia sehingga mengarah kepada larangan agama. Namun adanya unsur rohani berupa penggalan sholawat menjadikan lagu ini berbeda dari lagu rohani lainnya. Lagu ini mengajak penggemar untuk senantiasa berbuat baik dan selalu ingat akan Rasulullah. Karena dengan mengingat rasul melalui media musik dan sholawat, lagu ini juga sekaligus menambah nilai imanen di dalam setiap diri yang mendengarkannya. Purgatory membuat lagu ini tidak sekadar mencari audiens penikmat musik metal akan tetapi memiliki tujuan syiar agama yaitu mengingatkan sesama melalui musik mereka.

Seperti yang dikemukakan oleh Weinstein, tema-tema utama yang diusung oleh musik metal, antara lain: kekerasan, pemberontakan, kesewenang-wenangan, hubungan seksual, pemutarbalikkan, dan satanisme (Weinstein, 2000: 2). Kendati demikian, dengan aspek kebentukan musikal yang tetap identik dengan musik metal (distorsi gitar dan vokal yang berat dipadu dengan hentakan drum dan dentuman bass dalam ketukan yang terkesan kuat dan kokoh), Purgatory justru mencoba menampilkan tema-tema yang jelas bertolak belakang dengan tema-tema utama metal pada umumnya. Hal yang dilakukan oleh Purgatory dengan mengusung pesan-pesan Islami dengan iringan musik metal seolah dapat dipahami sebagai upaya "melawan kejahatan dengan cara-cara yang baik". Musik, termasuk metal, memang seringkali digunakan sebagai alat untuk menekan, mempengaruhi, dan protes. Mark LeVine mengatakan,

Music affords power to those who search for meaning," Bohlman argues, but the same music can be amplified in very different ways: heavy metal and hardcore rap are blasted by soldiers going into battle, and used on prisoners as part of "enhanced interrogation." 
But when the metal or rap is played by young people trying to resist or even transcend oppressive governments or societies, its power and potential are much more positive, reverberating far outside the scenes in which the music is embedded (LeVine, 2008: ii).

Repertoar musik metal yang mengusung tema-tema kekerasan dan sejenisnya merupakan bentuk kritik dan perlawanan terhadap situasi sekarang seolah para pelaku musik metal dengan cara frontal menolak ketidakadilan. Bahkan, Jeremy Wallach mengatakan bahwa kemunculan musik metal di Indonesia-yang ia sebut dengan underground music - antara lain sebagai respon terhadap keadaan demokrasi di negeri ini (Wallach, 2005: 17-18). Namun, Purgatory menampilkan kesan yang berbeda dengan cara yang dianggap bisa diterima oleh mayoritas penggemarnya dan mayoritas masyarakat Indonesia yang notabene pemeluk Islam. Dengan begitu, Purgatory bisa dikatakan menempuh jalan damai untuk menghadapi ketidakadilan dan membangun kesadaran diri secara pribadi agar bisa menjadi benteng terhadap hal-hal yang sifatnya negatif dan bukannya melontarkan kritik keras untuk melawan tindakan-tindakan kekerasan.

\section{Penutup}

Purgatory sebagai band metal memiliki ekosistem sendiri, termasuk di dalamnya bisnis musik dan penggemar. Dengan mengusung nilainilai religius Islami yang sejauh ini sangat bertolak belakang dengan tema-tema yang dibawakan oleh kelompok-kelompok musik metal, Purgatory tetap memiliki penggemar. Daya tarik Purgatory dan karya-karyanya ini muncul karena karya mereka memang memiliki kekhasan yang menampilkan ciri musik metal. Selain itu, karena adanya kesesuaian antara karya-karya mereka dengan keadaan masayarakat, Purgatory berani untuk menampilkan cara-cara perlawanan yang berbeda, melawan ketidakadilan dengan cara-cara yang benar, yakni mensyiarkan nilai-nilai kebaikan. Namun, ketiga dimensi ini tidak dapat dipisahkan satu sama lain secara kaku, melainkan saling terikat dan saling mendukung sehingga dapat menopang eksistensi
Purgatory di kalangan para pencinta musik metal di Jakarta.

\section{Kepustakaan}

Capper, A., \& Sifre, G. (2009). Heavy Metal in Baghdad: The Story of Acrassicauda. UK: Simon and Schuster.

Frishkopf, M. (2012). Sufi Music: The Rough Guide to Sufi Music. Asian Music, 43(1), 148-155.

George, K. M. (1998). Designs on Indonesia's Muslim Communities. The Journal of Asian Studies, 57(3), 693-713.

Harnish, D. (2003). Worlds of Wayang Sasak: Music, Performance, and Negotiations of Religion and Modernity. Asian Music, 34(2), 91-120.

Irawati, E. (2017). Transmisi Kelentangan dalam Masyarakat Dayak Benuaq. Resital Jurnal Seni Pertunjukan, 17(1), 1-18.

Ishak, A. H., \& Osman, M. R. (2016). A Systematic Literature Review on Islamic Values applied in Quality Management Context. Journal of Business Ethics, 138(1), 103-112.

Jouili, J. S. (2014). Refining the Umma in the shadow of the republic: Performing arts and new Islamic audio-visual landscapes in France. Anthropological Quarterly, 87(4), 1079-1104.

Laksono, K. L., Anggreni Purba, S., \& Dona Hapsari, P. (2015). Musik Hip-Hop sebagai Bentuk Hybrid Culture dalam Tinjauan Estetika. Resital Jurnal Seni Pertunjukan, 16(2), 75-83.

LeVine, M. (2008). Heavy metal Islam: Rock, resistance, and the struggle for the soul of Islam. USA: Crown.

Saeed, M., Ahmed, Z. U., \& Mukhtar, S.-M. (2001). International marketing ethics from an Islamic perspective: A value-maximization approach. Journal of Business Ethics, 32(2), 127-142.

Shaw, W. M. K. (2012). The Islam in Islamic art history: secularism and public discourse. Journal of Art Historiography, 6(1).

Stilt, K. (2010). Hisba, Arts and Craft in Islam. Arabisch-Islamische Welt in Tradition und 
Moderne. USA: American Oriental Society. Von Appen, R. (2007). On the aesthetics of popular music. Music Therapy Today, 8(1), 11.

Wallach, J. (2005). Underground Rock Music and Democratization in Indonesia. World Literature Today, 79(3), 16-20.
Weinstein, D. (2000). Heavy Metal: The Music and its Culture. UK: Perseus Books Group.

Weintraub, A. N. (2008). 'Dance drills, faith spills': Islam, body politics, and popular music in post-Suharto Indonesia. Popular Music, 27(3), 367-392. 